\title{
Advances and challenges in therapeutic monoclonal antibodies drug development
}

\author{
Mariana Lopes dos Santos', Wagner Quintilio', Tania Maria Manieri', Lilian Rumi Tsuruta ${ }^{1}$, \\ Ana Maria Moro ${ }^{1,2 *}$
}

\begin{abstract}
${ }^{1}$ Laboratory of Biopharmaceuticals in Animal Cells, Butantan Institute, São Paulo, SP, Brazil, ${ }^{2}$ Institute for Investigation in Immunology/INCT (National Institute for Science and Technology), São Paulo, SP, Brazil
\end{abstract}

\begin{abstract}
The use of serum containing polyclonal antibodies from animals immunized with toxins marked the beginning of the application of antibody-based therapy in late nineteenth century. Advances in basic research led to the development of the hybridoma technology in 1975. Eleven years later, the first therapeutic monoclonal antibody $(\mathrm{mAb})$ was approved, and since then, driven by technological advances, the development of mAbs has played a prominent role in the pharmaceutical industry. In this review, we present the developments to circumvent problems of safety and efficacy arising from the murine origin of the first mAbs and generate structures more similar to human antibodies. As of October 2017, there are $61 \mathrm{mAbs}$ and $11 \mathrm{Fc}$-fusion proteins in clinical use. An overview of all mAbs currently approved is provided, showing the development of sophisticated mAbs formats that were engineered based on the challenges posed by therapeutic indications, including antibody-drug conjugates (ADC) and glycoengineered mAbs. In the field of immunotherapy, the use of immunomodulators, bispecific mAbs and CAR-T cells are highlighted. As an example of promising therapy to treat infectious diseases, we discuss the generation of neutralizing monoclonal-oligoclonal antibodies obtained from human B cells. Scientific and technological advances represent mAbs successful translation to the clinic.
\end{abstract}

Keywords: Immunotherapy. CDR grafting. Phage display. Transgenic mice. Single B cell sorting.

\section{FROM THE THERAPEUTIC USE OF POLYCLO- NAL ANTIBODIES TO THE DISCOVERY OF MONOCLONAL ANTIBODIES}

The serum therapy introduced by Emil von Behring and Shibasaburo Kitasato in the late nineteenth century marked the beginning of the application of antibodybased therapy. They used serum containing polyclonal antibodies from animals immunized with diphtheria or tetanus toxins to treat these infectious diseases in other animals. The collaboration between von Behring and Paul Ehrlich resulted in the production of large amounts of antisera in animals and the experimental application of anti-diphtheria serum in humans, demonstrating the efficacy of the serum therapy as an effective antimicrobial therapy. Behring awarded the first Nobel Prize for

\footnotetext{
*Correspondence: Dr. Ana Maria Moro. orcid.org/0000-0002-0650-7764. Instituto Butantan, Laboratório Biofármacos em Células Animais. Av. Vital Brasil 1500 - 05503-900 - São Paulo, SP - Brasil. Tel.: +55 (11) 2627-9450. E-mail: ana.moro@butantan.gov.br
}

Physiology and Medicine in 1901 for his outstanding discoveries related to serum therapy especially against diphtheria (Kaufmann, 2017) opening a new perspective for the clinical handling of infections. The serum therapy or passive antibody therapy was largely used until early 30 's for a wide range of infectious diseases including pneumococcal pneumonia, meningococcal meningitis and others. Due to the discovery of antibiotics and their success for antimicrobial treatment, associated to problems of lot to lot variation, toxicity related to its heterologous origin and high cost for production, the serum therapy was gradually replaced. However, animal or human sera still represent a good alternative in cases with no available drugs (Casadevall, Dadachova, Pirofski, 2004) and unique for the neutralization of complex venom mixtures causing envenomation by biting accidents. The Instituto Butantan holds a portfolio of 13 equine hyperimmune antisera (Instituto Butantan, 2017). Human blood derivatives also pose limitations for wide applications (difficulty of large scale production, 
risk of disease transmission) and currently human blood antibodies are used only for specific purposes, e.g. antiRh for maternal-fetal incompatibility.

From 1940 the science related to antibodies revealed important insights such as antibody generation, its structure and diversity, Brunet's clonal selection theory stating that one cell produces one specific antibody (Cooper, 2015). These advances in basic research conducted to the development of the breakthrough hybridoma technology in 1975 generating hybrid cells secreting rodent-derived monoclonal antibodies (mAbs) in unlimited amount (Kohler, Milstein, 1975). The hybrid cells were obtained by the fusion of B cells originated from immunized animal with myeloma cells and the resultant selected single cell producing one specific antibody. The hybridoma technology awoke the interest for the application of antibodies in therapeutics again. However, the main targets were not infectious diseases as earlier, being directed to other conditions without efficacious drugs. The first therapeutic $\mathrm{mAb}$, muromonab, a $\mathrm{mAb}$ against $\mathrm{CD} 3$ receptor of T lymphocytes for the control of transplant rejection, was approved in 1986 by US Food and Drug Administration (FDA) and European Medicines Agency (EMA) (Norman et al., 1987). A completely new panorama was envisaged for the use of $\mathrm{mAbs}$ directed to - as magic bullets - a variety of targets, including ones related to chronic diseases in need of long term treatments. The success of muromonab anti-CD3 did not repeat for other indications, failing in safety and/or efficacy. One critical issue was the murine nature of the $\mathrm{mAbs}$ which induced adverse reactions and the immunogenicity response known as human anti-mouse antibodies (HAMA), anti-idiotypic or not (Hwang, Foote, 2005).

\section{MAKING POSSIBLE THE USE OF MONOCLO- NAL ANTIBODIES IN THE CLINIC}

To circumvent problems of safety and efficacy, decreasing their immunogenic potential, and make possible the therapeutic use of antibodies for long periods, techniques were developed to transform rodent antibodies into structures more similar to human antibodies without losing the binding properties to the target (Figure 1). Technical advances and knowledge increments in molecular biology field that started in the 70's with recombinant DNA technology allowed the production of recombinant antibodies by antibody engineering technologies (Almagro, Fransson, 2008). The first humanization approach led to generation of chimeric antibodies by combining sequences of murine variable domain with human constant region domain (Morrison et $a l ., 1984)$. The resultant antibody preserved the specificity and the immunogenicity was reduced, however still observed by the presence of human anti-chimeric antibody (HACA) in approximately $40 \%$ of patients (Hwang, Foote, 2005). Derived from this humanization approach, a chimeric anti-GPIIb/IIIa Fab fragment named abciximab that inhibits platelet aggregation in cardiovascular diseases was approved in 1994 by FDA, representing the second therapeutic mAb (Foster, Wiseman, 1998). It was followed by anti-CD20 rituximab, a chimeric IgG1 approved for non-Hodgkin's lymphoma in 1997, representing the first $\mathrm{mAb}$ with oncologic indication (Feugier, 2015).

One exceptional advance that increased the approval of therapeutic mAbs was the generation of humanized antibodies by complementary-determining region (CDR) grafting technique (Jones et al., 1986). By this technique

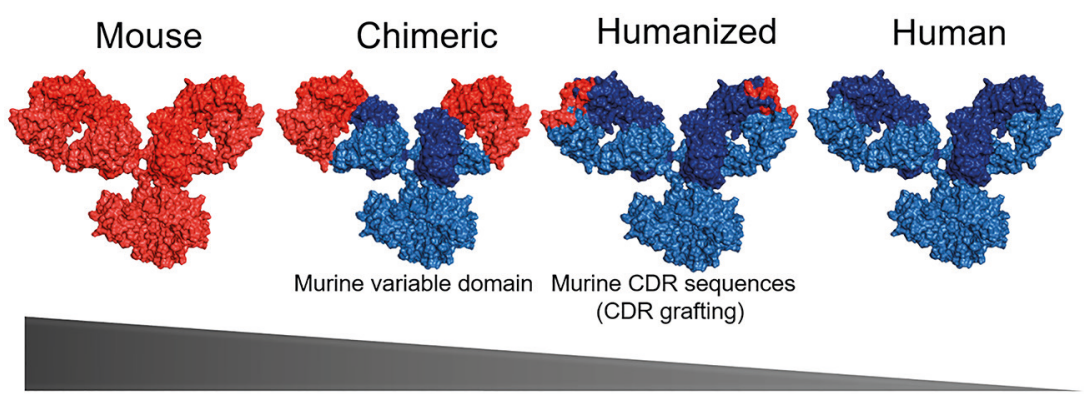

\section{Immunogenicity}

FIGURE 1 - Schematic overview of antibody humanization from murine antibodies (red domains) to fully human antibodies (blue domains). Chimeric antibodies are produced by combining sequences of a murine variable domain with human constant region domains. The murine CDR sequences transplanted to a human framework sequence produce humanized antibodies by the technique known as CDR grafting. Fully human antibodies are expected to be less immunogenic than chimeric and humanized antibodies. The images of the immunoglobulin structure (PDB code 1IGY) were created using PYMOL (The PyMOL Molecular Graphics System, Version 2.0 Schrödinger, LLC). 
the non-human antibody sequences of the CDR were transplanted to a human framework sequence (CDR grafting technique) expecting the maintenance of the specificity to the target (Jones et al., 1986) (Figure 1). To preserve the features of the original antibody such as the affinity and potency, this technique was improved by application of tridimensional modeling to the humanized antibody to identify the rodent residues impacting the target binding and so variants of the humanized $\mathrm{mAbs}$ were designed (Queen et al., 1989). The first CDRtransplanted humanized mAb approved by FDA in 1997 was the anti-IL2 receptor daclizumab with indication to prevent transplant rejection (Tsurushita, Hinton, Kumar, 2005). Other humanization techniques were developed to generate humanized antibodies (Almagro, Fransson, 2008), however, CDR grafting was considered the gold standard technique for therapeutic mAbs. The presence of human anti-humanized antibodies (HAHA) was verified in about $9 \%$ of humanized antibodies used clinically (Hwang, Foote, 2005). The techniques associated with antibody humanization turned possible the clinical use of a new class of biologics directed to complex diseases (autoimmune diseases and tumors) which require a long term treatment and also repeated doses of the drugs (Watier, Reichert, 2017).

\section{HUMAN MONOCLONAL ANTIBODIES FROM PHAGE DISPLAY AND TRANSGENIC ANIMALS}

Based on the success of humanized mAbs in the clinic, discovery technologies to obtain fully human mAbs started being developed in early 90's. At the middle of the 80's it was introduced the technology of in vitro display, a discovery platform for recombinant peptides and proteins. The first technology was phage display in which filamentous bacteriophages incorporated exogenous genes with diversity to compose a library, which content was presented on the phage surface as a fusion protein with a phage coat protein, allowing the selection of specific binders and affinity characteristics (Smith, 1985). This platform was applied for mAbs selection in the 90's using the format of antibody fragments (mainly scFv and Fab fragment) by the construction of libraries with antibody repertoire from various species, including the human repertoire (Figure 2). The main advances of this platform were the generation of antibody repertoire independent of in vivo immune response; the selection of human antibodies; the obtainment of mAbs against any kind of antigens such as self-antigens, toxic, unstable and non-immunogenic antigens and the possibility of affinity maturation of a candidate mAb (Frenzel, Schirrmann, Hust, 2016). Phage display technology was also used for antibody humanization through the guided selection technique. The first fully human therapeutic antibody anti-TNF $\alpha$ adalimumab - derived from this technique, was approved in 2002 by FDA for rheumatoid arthritis (Osbourn, Groves, Vaughan, 2005).

Transgenic animals represent another relevant discovery technology that started in the 90's to obtain fully human mAbs. Mice were genetically manipulated so that human immunoglobulin genes were inserted into their genome to replace the endogenous content, turning the immune system of these animals capable to synthesize fully human antibodies when immunized (Green, 2014). The large size of the human immunoglobulin loci was a challenge to the transgenic antibody technology. The production of similar or comparable repertoires to humans in transgenic mice requires diverse rearrangements combined with high expression of human V, D and J segments (Bruggemann et al., 2015). Different strategies have been used successfully to generate animals expressing human antibody repertoires (Lonberg et al., 1994; Mendez et al., 1997; Murphy et al., 2014). Although the number of fully human antibodies from transgenic mice has increased rapidly, the amount of platforms with approved drugs has remained limited. All the approved mAbs for therapeutic use are derived from 3 companies: Abgenix XenoMouse (purchased by Amgen in 2005), Medarex UltiMAb and HuMAb (purchased by Bristol Myers Squibb in 2009), and the more recent Sanofi/Regeneron VelociMouse ${ }^{\circledR}$ (LifeSci, 2017). Depending on the immunization protocol high affinity human antibodies can be obtained through selection of the clones generated mainly by the hybridoma technology protocol, after transgenic mice immunization. At the early stage of transgenic animal technology the targets were antigens with mAbs already in the market and the objective was to offer improved antibodies. As an example, we can cite the first approved in 2006 by FDA, panitumumab (anti-EGFR) followed by ofatumumab (anti-CD20). From 2009 mAbs for novel targets gained approval. As occurred to other discovery technologies, the transgenic mice platforms were improved along the time, and this fact contributed for their success, representing nowadays more than a half of the approved human mAbs.

\section{MONOCLONAL ANTIBODIES APPROVED TO DATE - CONVENTIONAL AND NEW FORMATS}

Since the first therapeutic $\mathrm{mAb}$, driven by technological advances, the development of monoclonal 


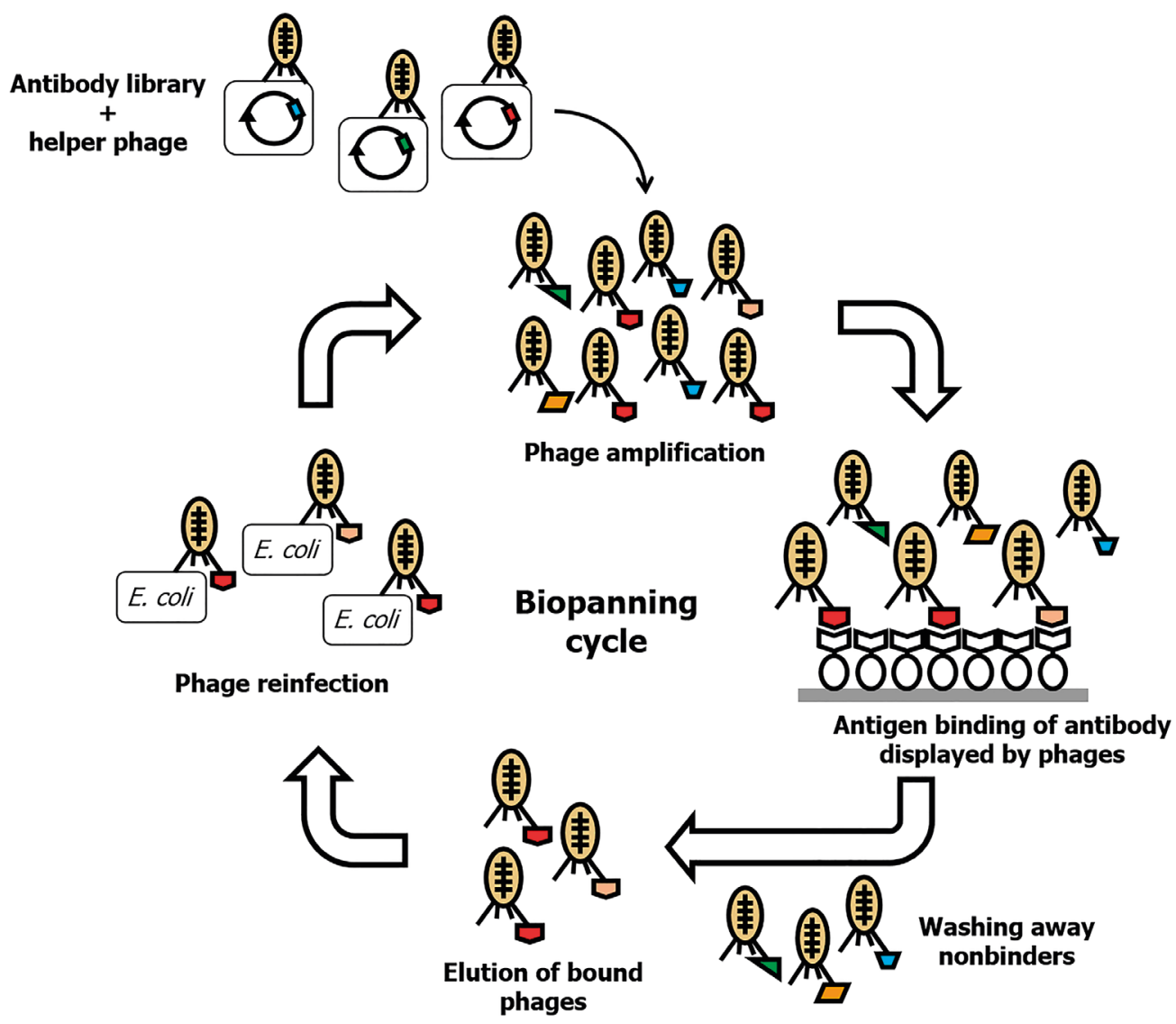

FIGURE 2 - Scheme of phage display technology for the selection of antibody fragments. The antibody library is amplified after transformation in E. coli and followed by the infection of helper phage to obtain phages displaying the antibody fragment. The phages are transferred to a surface coated with the chosen antigen. Bound phages are eluted and reinfect E.coli for a new selection round. After several rounds of the biopanning cycle, individual clones are selected from the enriched library, characterized and expressed recombinantly.

antibodies has played a prominent role in the pharmaceutical industry. The top 10 best-selling innovative drugs in 2016 comprised $5 \mathrm{mAbs}$ and $1 \mathrm{Fc}$-fusion protein that generated $\$ 53,599 \mathrm{M}$ in worldwide sales (Strohl, 2018). The number of mAbs (including Fc-fusion proteins) in late-stages clinical studies and approved for clinical use has increased rapidly and is expanding to new therapeutic areas. As of October 2017, a sum of $61 \mathrm{mAbs}$ and $11 \mathrm{Fc}$-fusion proteins are in the market after been approved by FDA and/or EMA (ACTIP, 2017; Lagasse et al., 2017; Strohl, 2018) (Figure 3A). A few mAbs approved in the past which were withdrawn are not considered in this total. In this review, the term "mAbs" includes the Fc-fusion proteins with IgG format.

Most of the mAbs currently in the clinic have been developed for the treatment of diseases as cancer (38.9\%), followed by autoimmune (25\%), genetic $(6.9 \%)$, infectious (5.5\%), asthma (4.2\%), cardiovascular (4.2\%), hematologic (4.2\%) and macular degeneration (2.8\%). Other indications $(8.3 \%)$ included transplant rejection
(2.8\%), bone loss, antidote, eczema and diabetes type 2 (Figure 3B). Half of the mAbs (36) in the market are of human origin, 18 generated in transgenic animals and 7 by phage display technology (Bruggemann et al. , 2015; Frenzel, Schirrmann, Hust, 2016; LifeSci, 2017), the other 11 are Fc-fusion proteins (Figure 3C). Humanized, chimeric and murine account for $34.7 \%, 12.5 \%$ and $2.8 \%$, respectively, of $\mathrm{mAbs}$ in clinical use (Figure 3C).

To date, all of the currently approved mAbs are of IgG isotype 1, 2, 4 or hybrid 2/4 (Figure 3D). The structure of the immunoglobulin (Ig) is important to elicit their function against self or foreign antigens. The four IgG subclasses have differences in the hinge region and variations in amino acids in the Fc domain (Brezski, Georgiou, 2016). The mAbs can interact with different Fc $\gamma$ receptors (Fc $\gamma \mathrm{Rs}$ ) depending on the IgG subclass, which strongly influences their functional activity and pharmacokinetics (PK) (Brezski, Georgiou, 2016; Wang, Mathieu, Brezski, 2018). IgG1 are the preferred IgG subclass for development of therapeutics 
A Approved Drugs

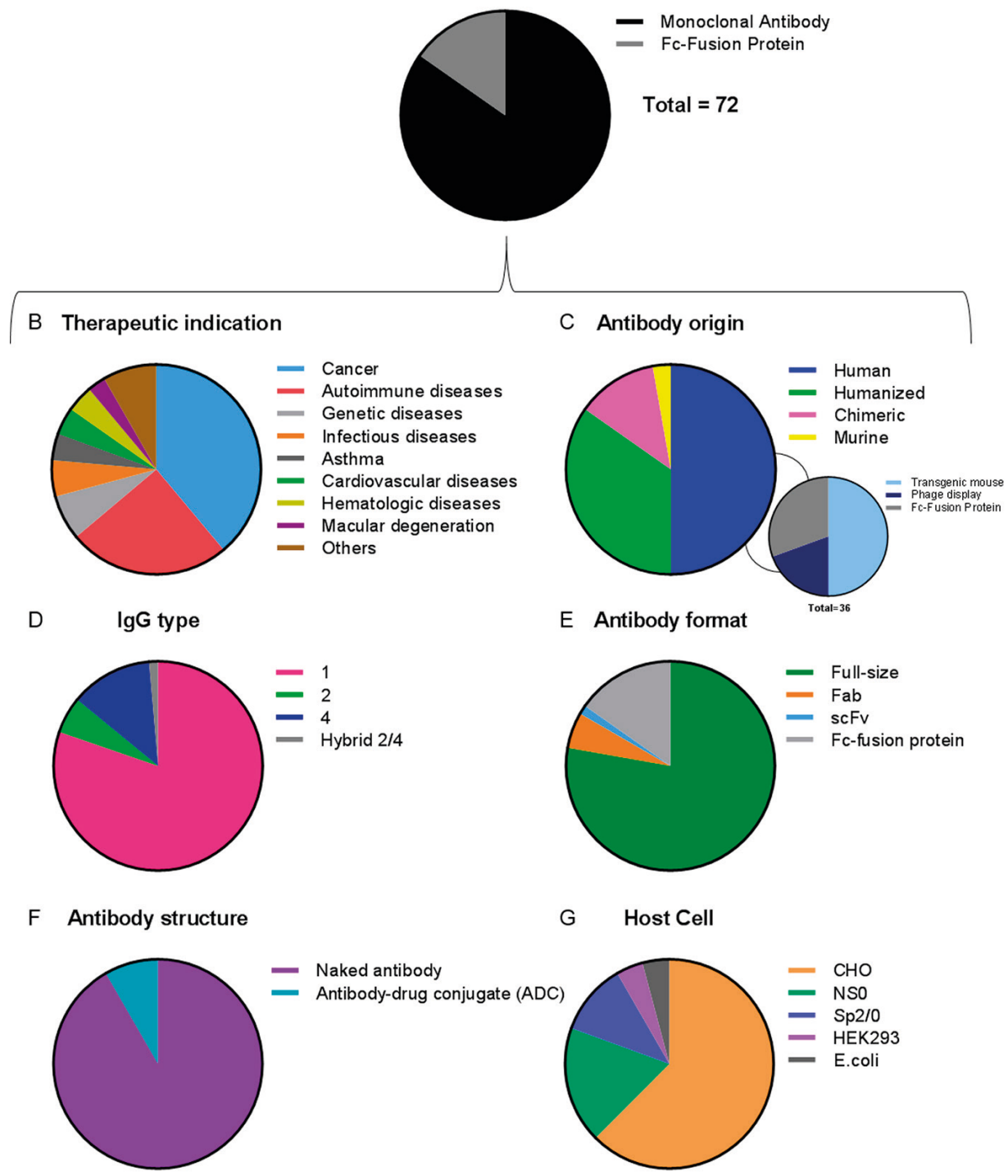

FIGURE 3 - Monoclonal antibodies (including Fc-fusion proteins) currently approved by FDA and/or EMA as of October 2017, classified by (A) type of molecule, (B) therapeutic indication, (C) antibody origin and the technology used for the development of human mAbs; (D) IgG type, (E) antibody format, (F) antibody structure and (G) host cell.

mAbs, representing $80.3 \%$ of mAbs currently in clinical use, followed by $\operatorname{IgG} 4(12.7 \%), \operatorname{IgG} 2(5.6 \%)$ and one hybrid IgG2/4 (1.4\%) mAb (Figure 3D). Although IgG3 displays the strongest ADCC (antibody-dependent cellular cytotoxicity) and CDC (complement-dependent cytotoxicity) effector functions of all IgG subclasses, at present there is no approved $\mathrm{IgG} 3 \mathrm{mAb}$; some reasons are the relatively short-life compared to the other IgG subclasses and the longer hinge that complicates bioprocessing (Stapleton et al., 2011; Brezski, Georgiou, 2016). The serum half-life is $\sim 23$ days for IgG1, IgG2 and $\mathrm{IgG} 4$, and 2-6 days for IgG3 (Saxena, Wu, 2016). Eculizumab, the IgG2/4 hybrid mAb approved in 2007 for the treatment of paroxysmal nocturnal hemoglobinuria $(\mathrm{PNH})$ relies on this construct to eliminate or reduce the effector function via Fc $\gamma$ Rs and complement binding, maintaining normal serum half-life. Considering that human IgG2 antibody isotype does not bind Fc $\gamma \mathrm{Rs}$ and $\mathrm{IgG} 4$ does not activate the complement cascade, eculizumab was formed by the $\mathrm{CH} 1$ and hinge regions of human $\mathrm{IgG} 2$ fused to the $\mathrm{CH} 2$ and $\mathrm{CH} 3$ regions of human IgG4 (Rother et al., 2007).

In relation to size-based structure, antibodies can be presented as an entire molecule or fragments. To date, there are only 5 antibody-fragments mAbs (6.9\%) approved, 4 antigen-binding fragments (Fab) and 1 single chain variable 
fragments (scFv). Full-size mAbs represent $77.8 \%$ of the $\mathrm{mAbs}$ in the clinic and $15.3 \%$ are Fc-fusion proteins (Figure $3 \mathrm{E})$. The development of antibody fragments sought to maintain the high specificity and selectivity, while offering advantages in manufacturing (time and costs) and additional functional benefits such as increased penetration than fulllength mAbs into target tumors or tissues. On the other hand, antibody-fragments lacks the Fc domain affecting the stability and therapeutic action of mAbs besides shorter circulating half-lives (Nelson, 2010). So far, there is only one $\mathrm{mAb}$ approved in the scFv format - blinatumomab - a bispecific T-cell engager (BiTE) antibody against CD19/CD3 approved in 2014 for the treatment of acute lymphoblastic leukemia (Smits, Sentman, 2016).

It is important to highlight the use of bispecific $\mathrm{mAbs}$ for retargeting $\mathrm{T}$ cells, in which one arm binds to the target cell (usually an antigen on a cancer cell) and one arm binds to activating receptors on cytotoxic cells, such as T or NK cells (usually T-cell surface glycoprotein CD3 $\varepsilon$-chain on T cells) (Weiner, 2015; Strohl, 2018). Bispecific antibodies are conceptually old (Davico Bonino et al., 1995) and advances in this technology in the past decade have led to a significant increase in the number of clinical candidates. Chimeric antigen receptor (CAR) $\mathrm{T}$ cell therapy is another approach employed for T-cell redirection to specifically target and destroy tumor cells. CAR-T cells are genetically engineered fusion proteins formed by a $\mathrm{mAb}$ variable region such as scFv, linked to a T-cell activating motif (Weiner, 2015; Levine et al., 2017; Strohl, 2018)(Figure 4). In August 2017, FDA approved the first CAR-T cells drug - tisagenlecleucel for the treatment of acute lymphoblastic leukemia (ALL) (Kymriah, 2017), and two months later, in October 2017, axicabtagene ciloleucel to treat adults with certain types of large B-cell lymphoma (Yescarta, 2017). Although these 2 $\mathrm{mAb}$-related drugs are composed by scFvs, they were not considered in Figure 3 because of their particular origin, from T-cells of individual patients. Briefly, leukocytes are removed from patient's blood by leukapheresis and enriched for $\mathrm{T}$ cells, which are engineered to express the chimeric antigen receptor (which reprograms the T cells to target tumor cells), expanded in a bioreactor system and concentrated to a volume that can be infused back into the patient (Levine et al., 2017) (Figure 4).

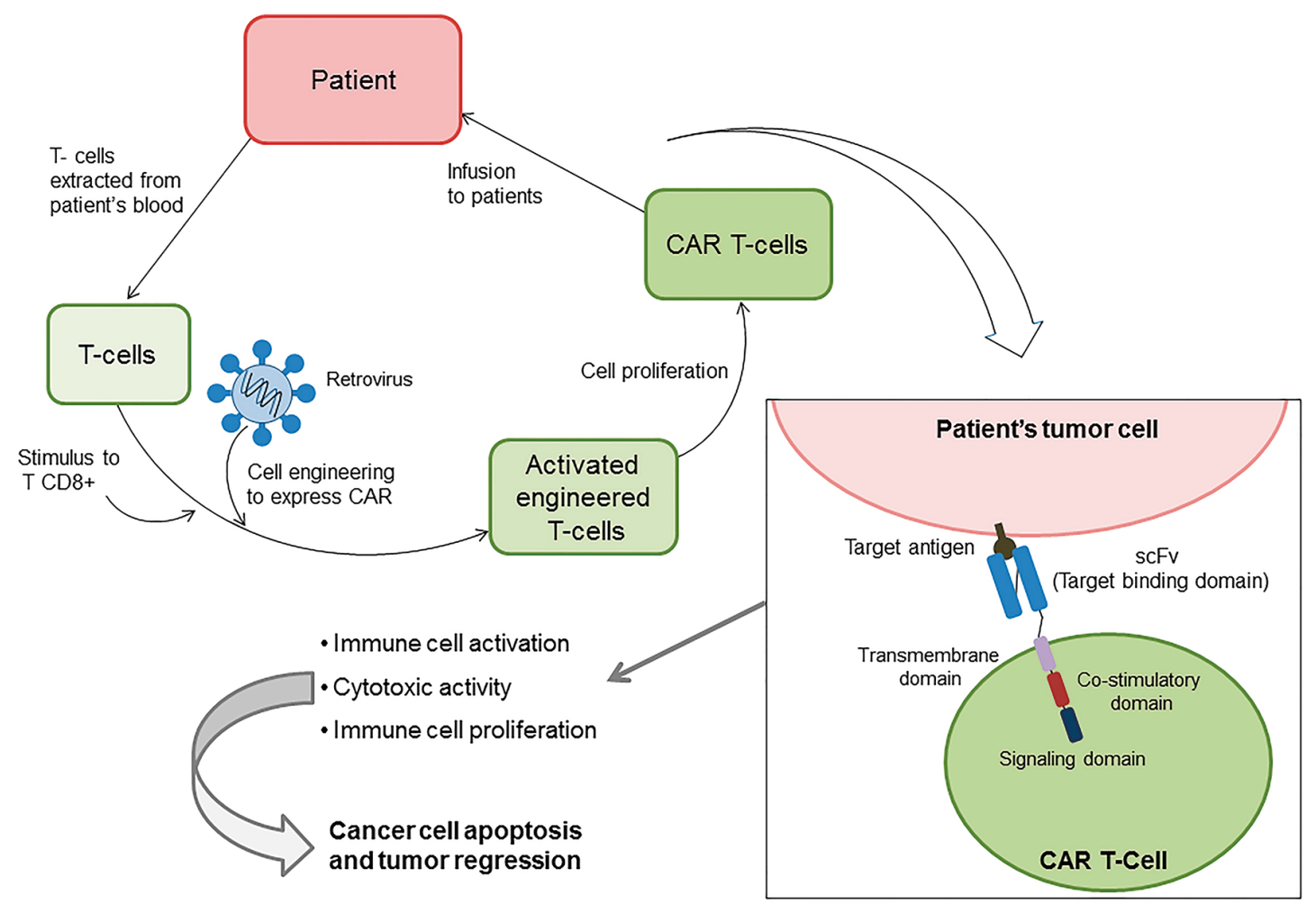

FIGURE 4 - CAR-T cell therapy. The patient's immune cells are first collected from the bloodstream by leukapheresis. In vitro, these cells are stimulated to express CD8 receptor and engineered by infection with a retrovirus containing genes of the chimeric antigen receptor which will be expressed by the TCD8+ cell - this CAR is basically a scFv against the tumor cell target linked to a transmembrane domain, a co-stimulatory domain (which enhances the immune response) and a signaling domain (responsible by the activation of the T cell) in tandem. The T cells are then expanded over 7-10 days and delivered back to the patient by intravenous infusion. Their bind to the tumor cell elicits the immune response leading to tumor death. 
In the field of cancer immunotherapy, an extraordinary way of interfering with the immune response was proposed by the development of mAbs capable of inhibition of immune checkpoints (antagonists of CTLA4, PD-1 and PD-L1) that act as immunomodulators (Figure 5 ) and can be used as single agent or in combination immunotherapy (Emens et al., 2017). By this approach the patient own immune response is enhanced to identify and destroy tumors in a strategy that can be applied for several types of cancers. The first immunomodulator $\mathrm{mAb}$ approved was the anti-CTL4 ipilimumab for metastatic melanoma in 2011 by FDA and EMA. CTL-4 (cytotoxic $\mathrm{T}$ cell lymphocyte-associated protein 4 ) inhibits the co-stimulatory signal of CD28 and ipilimumab restores CD28 activity promoting increase of the number of activated $T$ cells that leads to antitumor immune response (Ascierto, Marincola, 2014). Currently, there are also 2 CTLA4-Fc fusion proteins in clinical use: abatacept and belacept. Another class of immunotherapy that has been approved by FDA and EMA are the inhibitors of either the programmed death receptor 1 (PD-1) or its ligand (PDL1). PD-1 as well as CTLA4 are expressed on activated T cells, with CTLA4 binding to CD80/CD86 on APC (antigen presenting cells) and PD-1 binding to PD-L1 on tumor cells. These mAbs target and block the inhibitory interactions acting as suppressor of the antitumor response (Alsaab et al., 2017). To date, 2 anti-PD-1 mAbs -pembrolizumab and nivolumab - were approved by FDA and EMA in 2014/2015. Later, 3 anti-PD-L1 mAbs received marketing authorization from FDA, atezolizumab in 2016 and avelumab and durvalumab in 2017 (Alsaab et al., 2017; Strohl, 2018) (Figure 5).

Antibody-drug conjugates (ADCs) emerged as a promising anticancer treatment agent combining the specificity and selectivity of mAbs with the cytotoxic potency of chemotherapy. Although the ADCs have been under investigation for decades, recently advances in conjugation and linker technologies have enabled the development of more stable, effective and safe ADCs (Peters, Brown, 2015). Currently, 8.3\% of all approved $\mathrm{mAbs}$ in the clinics are ADCs while the majority (91.7\%) functions as naked antibodies or in combination with chemotherapeutics (Figure 3F). The conjugation to exogenous functional moieties is also an alternative used to extend the half-life of fragments, which was the strategy used in the anti-TNF $\alpha$ PEGylated Fab certolizumab pegol (Nelson, 2010).

MAbs have been produced by a wide variety of platforms including mammalian and non-mammalian expression systems. The choice of the most appropriate platform depends on the protein to be expressed. For $\mathrm{mAb}$ manufacturing, mammalian expression systems are, generally, the preferable choice since such cell lines are able to produce large, complex proteins with post-translational modifications (PTMs), in special glycosylation. A major fraction of the currently $\mathrm{mAbs}$ in clinical use was generated in Chinese hamster ovary (CHO) cells $(62.5 \%)$, followed by murine myeloma cells NS0 (18\%) and Sp2/0 (11.1\%),

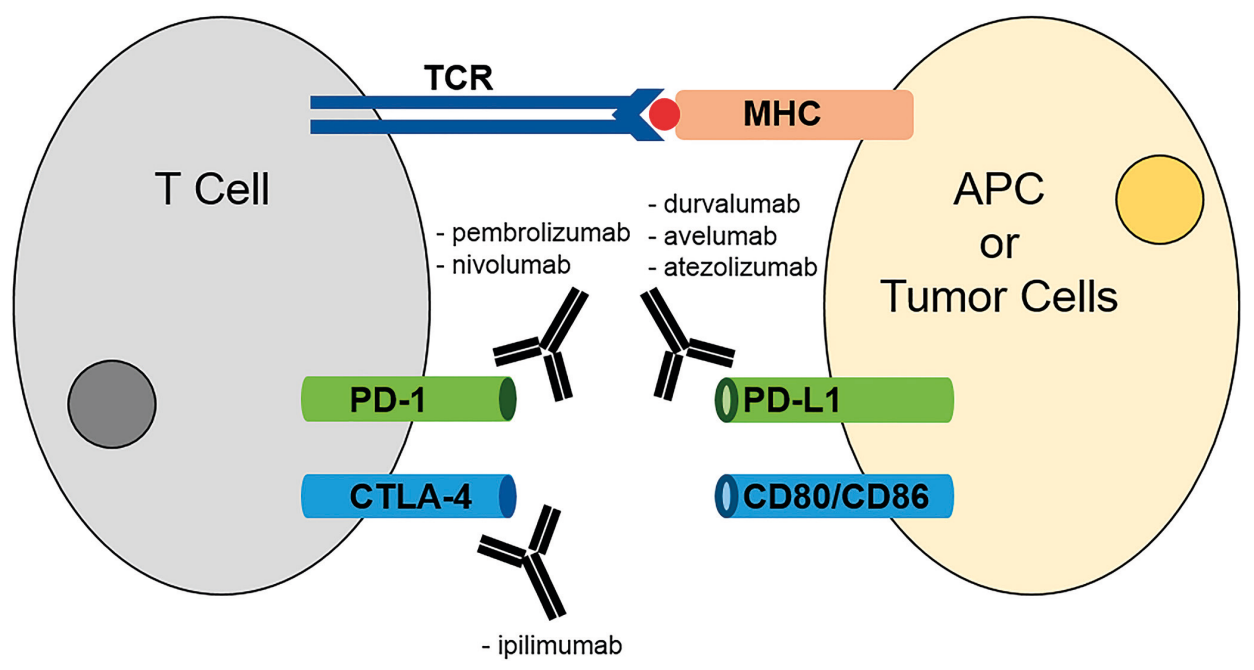

FIGURE 5 - MAbs targeting immune checkpoints. The recognition of tumor cells by antigen presenting cells (APCs) leads to T cell activation by MHC-antigen interactions with T-cell receptors. CTLA-4 and PD-1 are co-inhibitory checkpoint receptors expressed on activated T-cells which downregulate immune response. The binding of CTLA-4 to its ligands CD80/CD86 on APCs and the interaction PD-1/PD-L1 on tumor cells result in inhibition of T-cell antitumor response. MAbs targeting CTLA-4 (ipilimumab), PD-1 (pembrolizumab and nivolumab) and PD-L1(durvalumab, avelumab and atezolizumab) block these immunoinhibitory interactions thus enhancing antitumor response. 
human embryonic kidney 293 (HEK 293) cell line (4.2\%) and Escherichia coli (4.2\%) (Figure 3G). So far, the approved mAbs produced in human cells (HEK293) are $3 \mathrm{Fc}$-fusion proteins of the coagulation factors VIII (efmoroctocog alfa) and IX (eftrenonacog alfa) for the treatment of hemophilia A and B, respectively, and glucagon-like peptide-1 (GLP-1) (dulaglutide) for the treatment of type 2 diabetes (Dumont et al., 2016).

Antibody engineering technologies allowed the development of mAbs with binding, functional and pharmacological characteristics suitable for its therapeutic use. Initially the focus of antibody engineering was the manipulation of the variable regions for humanization and affinity-maturation of antibodies, or the generation of different types of antibody fragments such as Fab and $\mathrm{scFv}$ (Strohl, 2018). Then, the focus turned to the improvements of the Fc functions, such as the increase of ADCC, ADCP (antibody-dependent cellular phagocytosis) and CDC (Brezski, Georgiou, 2016; Strohl, 2018), or the silencing of Fc functions (Strohl, 2018). Fc engineering has emerged as an important tool for developing mAbs with enhanced specific activity and longer half-life, which could reduce dosage and potential side effects (Sondermann, Szymkowski, 2016). To date, there are 3 approved antibodybased molecules with reduced Fc functionality and 2 glycoengineered $\mathrm{mAbs}$ with enhanced ADCC activity. The CTL4-Fc abatacept and belatacept have modified hinges and the anti-C5 mAb eculizumab has a hybrid Fc IgG2/IgG4; all of them aiming to reduce $\mathrm{Fc}$ functionality to increase safety margin as these $\mathrm{mAbs}$ bind to immune system components (Strohl, 2018). The first glycoengineered $\mathrm{mAb}$ to receive marketing approval was mogamulizumab, a defucosylated anti-CCR4 mAb approved in Japan (under FDA review) for patients with relapsed or refractory CCR4-positive adult T-cell leukemia-lymphoma. The depletion of fucose residues - which are responsible for adverse effects on antibodies' effector function - from oligosaccharides in the antibody Fc region has shown to enhance mogamulizumab ADCC activity by up to 100 fold (Beck, Reichert, 2012). Obinutuzumab, an anti-CD20 mAb with low fucose content, was approved by FDA and EMA for the treatment of chronic lymphocytic leukemia (CLL) (Golay et al., 2013).

\section{NEUTRALIZING MONOCLONAL-OLIGO- CLONAL ANTIBODIES TO TREAT INFEC- TIOUS DISEASES}

It draws attention when analyzing the approved $\mathrm{mAbs}$ that the majority target cancer and autoimmune diseases, while some are directed to other conditions and very few address infectious diseases. To treat infectious diseases the direct isolation of antibodies from humans instead of humanization from other animals is preferred wherever possible. Human B cells are nowadays largely and commonly used as starting material to isolate human mAbs through methodologies such as in vitro display techniques, $B$ cells immortalization and single $B$ cell expression cloning (Wilson, Andrews, 2012). Neutralizing human antibodies to fight infectious agents are potentially more efficient if derived directly from human B lymphocytes, as heavy chain and light chain pairing is already selected in vivo after rearrangement and have been tolerized in humans, either following infection or vaccination. There are currently two major approaches to secure the production of human mAbs derived from $\mathrm{B}$ lymphocytes, by the immortalization of selected B cells and/or the capture and sorting of specific B cells followed by amplification of the $\mathrm{mAb}$ variable chains expressed by the single B cell. Attempts of immortalization of B lymphocytes with the lymphotropic herpesvirus Epstein-Barr virus (EBV), converting the normal B cells into established cell line, started soon after the hybridoma technology discovery. Its potential was hampered by major issues like the source of human lymphocytes, the lack of a suitable human myeloma fusion partner and the instability of EBV transformed B cells. Twenty years ago we tried to obtain human mAbs from splenocytes derived from a spherocytosis patient, who had undergone several blood transfusions and eventually splenectomy. The overall EBV infection efficiency was very high and the cells were submitted to cloning by limiting dilution. The supernatants of primary cultures were assayed by indirect immunofluorescence against a panel of several human cell lines and primary cells, resting or activated. One of the clones produced an IgM/K antibody that was identified by several criteria to be an anti-Tn antigen, reacting with both Tn $\alpha$ and $\beta$ antigens, when tested against a panel of glycoproteins by ELISA. As Tn being a surface antigen in many tumors, a small number of tumor cell lines was tested, resulting positive by immunohistochemical staining for A549 (lung tumor). The efforts to hybridize the clone with human K6H6 heteromyeloma were unsuccessful and after 4 months there was decay in mAb production, albeit the cells continued to grow vigorously (Moro AM, unpublished results).

The major source of human B lymphocytes however is the peripheral blood which not always contains memory cells preferentially allocated in lymphoid organs. Unfruitful trials were made to immunize human peripheral blood cells in vitro, either to present the antigen or to improve the binding affinity. Although a suitable human myeloma fusion partner was never successfully established, some groups obtained stable human mAbs 
producing hybridomas after fusion of EBV transformed cells with non-secreting murine-human heteromyelomas, e.g., HMMA 2.5 (Gorny, 2012). Electrofusing EBV transformed B cells to the HMMA 2.5 heteromyeloma was an efficient way for Yu et al. (2008) to obtain human neutralizing mAbs from elderly people that had survived the 1918 influenza pandemia. Rescuing specific B cells from peripheral blood with recombinant 1918 haemagglutinin protein antigen in 8 out of 32 candidates after nearly 90 years proved the occurrence of functional adaptive immunity to the pandemic virus (Yu et al., 2008).

A recent technology is based on the expression of the antibody heavy and light genes captured from a single B lymphocyte, through the protocol of immunophenotyping, cell sorting, RT-PCR (reverse transcriptase polymerase chain reaction), sequencing, cloning in plasmids containing the gene sequences of light and heavy constant chains and transfection into mammalian cells (Scheid et al., 2009). Taking advantage of both techniques, some groups have combined EBV transformation of B cells and recombinant expression of derived $\mathrm{mAbs}$ as a practice to express $\mathrm{mAbs}$ targeting influenza viruses. To understand and evaluate the immunization efficacy of influenza viruses vaccine, heterosubtypic neutralizing $\mathrm{mAbs}$ were obtained by first sorting out B cells from individuals vaccinated against seasonal influenza following by the transformation of the specific B cells with EBV virus (Corti et al., 2010). The transforming of these single $\mathrm{B}$ cells meant to avoid the large work of RT-PCR amplification of both light and heavy chain genes for each B cell, sequencing, cloning and transfecting into a mammalian cell. Another complex combination of techniques gave rise to a $\mathrm{mAb}$ that recognizes a novel and conserved epitope on the globular head of H1N1 virus haemagglutinin. In this case, human peripheral blood mononuclear cells were transformed with EBV virus with additives for efficiency enhancement and the selected B cells were fused to HMMA2.5 heteromyeloma following by limiting dilution cloning. The mRNA of the hybridomas was extracted with selected primers, cDNA was prepared, amplified and cloned into mammalian cells for recombinant expression (Krause et al., 2011).

Besides the potential for therapy, human mAbs from vaccinated or infected individuals offer the opportunity to gain knowledge on how the immune system responds to one or other situation and how vaccines can be developed or improved to add efficiency and safety to immunized populations. The study of clonal lineages and amplitude of influenza neutralization found in repertoires of infected and vaccinated individuals could provide guidance for design of influenza vaccines capable of inducing immunodominant broadly cross-reactive antibody responses (Moody et al., 2011). The new approved composition of 4 monovalent viruses to influenza vaccination was proposed by Lee et al. (2016) due to the results found in the serological repertoire elicited to each of the 3 monovalent components evaluated in pre- and post-vaccination samples, through a new technological approach which combines high-resolution proteomics analysis of immunoglobulins (Ig-seq) and high-throughput sequencing of transcripts encoding B cell receptors (BCR-seq) (Lee et al., 2016). In the case of influenza, neutralizing antibodies can be captured either from vaccinated or infected people, even rescuing responses to the 1918 pandemia (Yu et al., 2008).

The case of viral infections with no available vaccines as HIV and arboviruses, poses interesting and intriguing scientific questions: a few HIV chronic infected individuals never develops AIDS and 4 serotypes of dengue viruses elicit neutralizing and enhancing antibodies. Different neutralizing human anti-HIV mAbs were reported in recent years, giving a promise for treatment, vaccine design and eradication, reviewed by Stephenson and Barouch (Stephenson, Barouch, 2016). High affinity $\mathrm{mAbs}$ obtained from $\mathrm{B}$ cells from chronically infected people have matured in vivo against different viral epitopes, CD4 cells binding site, glycan-dependent site on the virus envelope. The $\mathrm{Fc}$ functionality, mediating the killing of infected cells has been demonstrated as an important feature of the neutralizing anti-HIV $\mathrm{mAbs}$. Different $\mathrm{mAb}$ candidates have been screened in preclinical and/or clinical studies so far, showing good tolerability and potency (Stephenson, Barouch, 2016).

Neutralizing mAbs against arboviruses have been generated from B cells of infected convalescent people. Using a double screening to capture B cells committed to make antibodies against dengue viruses, Smith et al. obtained 50 human $\mathrm{mAbs}$ exhibiting different unique neutralization potencies, binding to different sites and also enhancing $\mathrm{mAbs}$ which can be of great value in rational dengue viruses vaccine design (Smith et al., 2014). Human mAbs obtained by B cells of naturally infected people are under in vivo testing in mice, demonstrating protection for Chikungunya virus (Fric et al., 2013). Highly neutralizing human mAbs just described have the potential for impeding the maternal-fetal transmission of Zika virus (Robbiani et al., 2017).

\section{TECHNOLOGICAL CHALLENGES TO PRO- DUCE BETTER ANTIBODIES}

Therapeutic mAbs, albeit highly efficient as magic bullets, are not devoid of occurrence of adverse reactions 
in patients. From just transient anti-drug antibodies (ADA) without any clinical relevance to serious effects including anaphylaxis and premature drug clearance interfering in the drug PK properties (Chirmule, Jawa, Meibohm, 2012), the immunological effects of mAbs may be caused by several factors, either patient's or drug related: genetic background, previous immunity, drug schedule, manufacturing process, formulation and molecular characteristics (Jefferis, 2016). Fully human monoclonal antibodies are conceptually less immunogenic than chimeric or humanized. However, adalimumab, e.g., is known to induce ADA in up to $30 \%$ of the patients (Bartelds et al., 2007; Goupille, 2016). In this case, these responses can be T-cells dependent, i.e. small linear sequences (9-mer) in the therapeutic protein may bind to the major compatibility complex activating the presentation to the compatible cells thus eliciting the immunogenic response. In this context, there are many approaches to identify and suppress CD4+ T cell epitopes within the protein sequence. According to a search on the online tool PubMed, from January 2012 to November 2017 using the keywords "T-cell epitope prediction" 209 articles were found from vaccine design to therapeutic proteins deimmunization. In silico processes are based in computer algorithms able to analyze the protein sequences mapping the MHC-I and II restricted T cell epitopes (Weber et al., 2009; Delluc, Ravot, Maillere, 2011). Ex vivo identification of CD4+ T epitopes has been successfully applied to identify the immunogenic sequences in infliximab and rituximab (Hamze et al., 2017) both chimeric monoclonal antibodies. Once identified, epitopes may be engineered as a less immunogenic molecule.

The optimization of the binding epitope relies mainly in the right selection during the antibody selection step. In vivo, this affinity maturation depends on and is limited to response to the antigen (Batista, Neuberger, 1998) and improvements in the affinity can be achieved by the called in vitro affinity maturation, including random or targeted mutagenesis (Chowdhury, 2003) and shuffling approach (Schmohl et al., 2017) to manipulate DNA sequence and obtain a panel of antibodies with different affinities from the parental molecule. After, the selected molecule may be optimized to increase the binding affinity. In silico molecular modelling is an important tool to simulate the interaction to the target and then identify the candidate amino-acid for replacement to increase the binding (Balint, Larrick, 1993; Lamdan et al., 2013). Moreover, the affinity may be tailored considering the electrostatic interaction between $\mathrm{mAb}$ and antigen to increase affinity up to 140fold (Lippow, Wittrup, Tidor, 2007).

Although engineered mAbs have been showing better functional characteristics, the stability of these drugs is still a matter of concern. There are two ways mostly used for stabilizing a protein-based drug. The first one is the improvement of the formulation conditions by addition of stabilizers, as surfactants (Agarkhed et al., 2018); the second and widely studied strategy is to improve the molecule structure through protein engineering. By the introduction of $\mathrm{N}$-glycan sites on the constant region of the Fab domain of bevacizumab, the resulting glycosylation was found to stabilize the protein structure without activity loss (Courtois et al., 2016). The strategy is to identify the key spots for mutation. Substitutions of native for charged amino acids were seen to increase the thermal stability of proteins. This tool emerged as a powerful methodology, with the caution that mutations can also result in negative effects caused by unexpected changes in the activity of the molecule (Lawrence, Phillips, Liu, 2007). By structure-based computational design methods, theoretical approaches have been used to predict unwanted events and consequently focus only on beneficial substitutions. This method uses existing or predicted protein structures to identify aggregation-prone regions (Chennamsetty et al., 2009) along with molecular biology techniques resulting in the creation of new antibodies (Miklos et al., 2012; De Nardis et al., 2017) and also biobetters, improved versions of original mAbs (Courtois et al., 2016).

\section{PERSPECTIVES}

Antibody-based therapy has continuously evolved since the initial discovery. Nowadays therapeutic mAbs represent the principal biological drugs in development, in clinical trials and in the market. It is clear that mAbs and fusion proteins play a leading role in the pharmaceutical industry and market. A recent review (Strohl, 2018) that compiled the number of $\mathrm{mAbs}$ in clinical studies showed 575 in Phase I/II and 70 in Phase III. Only for bispecific formats, there are at least 61 in clinical trials, generated through not less than 24 different technology platforms (Strohl, 2018). The ability to engineer $m A$ bs to fine-tune their properties for nearly any application has opened a promising horizon for this class of therapeutic drugs. Their use revolutionized the treatment of human diseases acting in various kinds of targets and mechanisms. Novel discovery technologies and antibody engineering techniques are being developed and existing technologies have been improved to obtain new therapeutic mAbs. The expectation is that in the near future new mAbs will be approved giving more potent treatment options for the patients. Targets unexplored until recently might make striking differences with mAbs in advanced stages of evaluation for new therapeutic indications such as 
Alzheimer's disease (Rygiel, 2016), which urgently needs new treatment alternatives.

In addition to the innovative $\mathrm{mAbs}$, the biosimilars versions are growing rapidly powered by patent expiration of blockbusters mAbs such as the best-selling anti-TNF $\alpha$ adalimumab, with worldwide sales of 16 billion dollars in 2016 (Strohl, 2018). To date, from the 11 biosimilar mAbs approved by the FDA and/or EMA, 7 of them are anti-TNF $\alpha$ drugs. The most recent approval was on December 1, 2017 by the FDA of the biosimilar version of trastuzumab for the treatment of breast and stomach cancers (Ogivri, 2017). This is the second biosimilar approved in the U.S., after bevacizumab for treatment of cancer and the first for these two types of tumor (Mvasi, 2017). The approval of biosimilars by regulatory agencies depends on the demonstration of no clinically significant differences in safety, purity and potency compared to the reference product. Differences in the glycosylation pattern usually occurs and must be proven to be clinically irrelevant (Tsuruta, Lopes Dos Santos, Moro, 2015).

Considering the expression system, most of the approved mAbs are expressed by rodent cells. Human cell lines able to accomplish complete human post translation modified proteins as HEK cells had Fc-fusion drugs approved more recently. The PER.C6 cells, of human origin as well, have been used in the development of innovator mAbs (Lopes dos Santos et al., 2013; Tsuruta et al., 2016). Parallel developments claim that plants might represent increased production capacity and, trying to surpass immunogenic potential, plant cells have been engineered to express human transferases (Komarova et al., 2017). Z-mapp, a product consisting of a combination of 3 humanized mAbs targeting Ebola virus was produced in tobacco plant and used on a compassionate basis during the Ebola epidemics in Africa (Chen, Davis, 2016). Yet to reach therapeutically less accessible or cryptic epitopes to conventional antibody formats, the atypical paratope of camelids and bovines, displaying unique structure features, have gained interest and studies for humanizing these formats are in course (Muyldermans, Smider, 2016).

A recent approach for the clinical use of $\mathrm{mAbs}$ relies on the combination of antibodies - oligoclonal mixtures - usually against a single target related to cancer or infectious diseases (Ellebaek et al., 2016; Strohl, 2018). Several studies indicate the synergistic effect of individual $\mathrm{mAbs}$ to enhance the virus or toxins neutralization, somehow playing the same role as polyclonal antibodies selected in vivo to fight infections. A mix of anti-HIV neutralizing mAbs obtained by different laboratories is under preclinical testing (Stephenson, Barouch, 2016). MAbs cocktails could potentially be administered at lower doses, reducing costs while increasing efficacy and safety (Diamant et al., 2015). The combination of mAbs into a single product aims to overcome heterogeneity and plasticity of antigens (Corti, Kearns, 2016).

Antibody therapy has come a long way since the approval of the first murine $\mathrm{mAb}$ in 1986. Public and private investments in $\mathrm{mAb}$-based therapy have never been so great, and the speed of progress not so fast as nowadays. For the 74 currently approved mAbs, considering $11 \mathrm{Fc}$-fusion proteins and 2 CAR-T cells, 7 $(9.5 \%)$ were approved in the 90 's, 18 (24.3\%) from 2000 to 2010 and $49(66.2 \%)$ received marketing authorization since 2011 , with 29 of them $(59.2 \%)$ in the last 3 years (2015-2017). This spectacular scenario holds promise for a steady growth in therapeutic possibilities.

\section{ACKNOWLEDGMENTS}

To the Brazilian National Research Council (CNPq) for Productivity Fellowship (307636/2016-0) to A.M.M.

\section{REFERENCES}

ACTIP. Animal Cell Technology Industrial Platform. Monoclonal Antibodies Approved by the EMA and FDA for Therapeutic Use (status 2017). 2017 [cited 2017 October 31]. Available from: http://www.actip.org/products/monoclonalantibodies-approved-by-the-ema-and-fda-for-therapeutic-use/.

Agarkhed M, O’Dell C, Hsieh MC, Zhang J, Goldstein J, Srivastava A. Effect of surfactants on mechanical, thermal, and photostability of a monoclonal antibody. AAPS PharmSciTech. 2018;19(1):79-92.

Almagro JC, Fransson J. Humanization of antibodies. Front Biosci. 2008;13:1619-1633.

Alsaab HO, Sau S, Alzhrani R, Tatiparti K, Bhise K, Kashaw SK, et al. PD-1 and PD-L1 checkpoint signaling inhibition for cancer immunotherapy: mechanism, combinations, and clinical outcome. Front Pharmacol. 2017;8:561.

Ascierto PA, Marincola FM. What have we learned from cancer immunotherapy in the last 3 years? J Transl Med. 2014;12:141.

Balint RF, Larrick JW. Antibody engineering by parsimonious mutagenesis. Gene. 1993;137(1):109-118. 
Bartelds GM, Wijbrandts CA, Nurmohamed MT, Stapel S, Lems WF, Aarden L, et al. Clinical response to adalimumab: relationship to anti-adalimumab antibodies and serum adalimumab concentrations in rheumatoid arthritis. Ann Rheum Dis. 2007;66(7):921-926.

Batista FD, Neuberger MS. Affinity dependence of the B cell response to antigen: a threshold, a ceiling, and the importance of off-rate. Immunity. 1998;8(6):751-759.

Beck A, Reichert JM. Marketing approval of mogamulizumab: a triumph for glyco-engineering. MAbs. 2012;4(4):419-425.

Brezski RJ, Georgiou G. Immunoglobulin isotype knowledge and application to Fc engineering. Curr Opin Immunol. 2016;40:62-69.

Bruggemann M, Osborn MJ, Ma B, Hayre J, Avis S, Lundstrom $\mathrm{B}$, et al. Human antibody production in transgenic animals. Arch Immunol Ther Exp (Warsz). 2015;63(2):101-108.

Casadevall A, Dadachova E, Pirofski LA. Passive antibody therapy for infectious diseases. Nat Rev Microbiol. 2004;2(9):695-703.

Chen Q, Davis KR. The potential of plants as a system for the development and production of human biologics. F1000Res. 2016;5(912).

Chennamsetty N, Voynov V, Kayser V, Helk B, Trout BL. Design of therapeutic proteins with enhanced stability. Proc Natl Acad Sci USA. 2009;106(29):11937-11942.

Chirmule N, Jawa V, Meibohm B. Immunogenicity to therapeutic proteins: impact on PK/PD and efficacy. AAPS J. 2012;14(2):296-302.

Chowdhury PS. Engineering hot spots for affinity enhancement of antibodies. Methods Mol Biol. 2003;207:179-196.

Cooper MD. The early history of B cells. Nat Rev Immunol. 2015;15(3):191-197.

Corti D, Kearns JD. Promises and pitfalls for recombinant oligoclonal antibodies-based therapeutics in cancer and infectious disease. Curr Opin Immunol. 2016;40:51-61.

Corti D, Suguitan AL, Jr., Pinna D, Silacci C, FernandezRodriguez BM, Vanzetta F, et al. Heterosubtypic neutralizing antibodies are produced by individuals immunized with a seasonal influenza vaccine. J Clin Invest. 2010;120(5):1663-1673.
Courtois F, Agrawal NJ, Lauer TM, Trout BL. Rational design of therapeutic mAbs against aggregation through protein engineering and incorporation of glycosylation motifs applied to bevacizumab. MAbs. 2016;8(1):99-112.

Davico Bonino L, De Monte LB, Spagnoli GC, Vola R, Mariani M, Barone D, et al. Bispecific monoclonal antibody anti-CD3 x anti-tenascin: an immunotherapeutic agent for human glioma. Int J Cancer. 1995;61(4):509-515.

De Nardis C, Hendriks LJA, Poirier E, Arvinte T, Gros P, Bakker ABH, et al. A new approach for generating bispecific antibodies based on a common light chain format and the stable architecture of human immunoglobulin G1. J Biol Chem. 2017;292(35):14706-14717.

Delluc S, Ravot G, Maillere B. Quantitative analysis of the CD4 T-cell repertoire specific to therapeutic antibodies in healthy donors. FASEB J. 2011;25(6):2040-2048.

Diamant E, Torgeman A, Ozeri E, Zichel R. Monoclonal antibody combinations that present synergistic neutralizing activity: a platform for next-generation anti-toxin drugs. Toxins (Basel). 2015;7(6):1854-1881.

Dumont J, Euwart D, Mei B, Estes S, Kshirsagar R. Human cell lines for biopharmaceutical manufacturing: history, status, and future perspectives. Crit Rev Biotechnol. 2016;36(6):1110-1122.

Ellebaek S, Brix S, Grandal M, Lantto J, Horak ID, Kragh M, et al. Pan-HER-An antibody mixture targeting EGFR, HER2 and HER3 abrogates preformed and ligand-induced EGFR homoand heterodimers. Int J Cancer. 2016;139(9):2095-2105.

Emens LA, Ascierto PA, Darcy PK, Demaria S, Eggermont AMM, Redmond WL, et al. Cancer immunotherapy: Opportunities and challenges in the rapidly evolving clinical landscape. Eur J Cancer. 2017;81:116-129.

Feugier P. A review of rituximab, the first anti-CD20 monoclonal antibody used in the treatment of B non-Hodgkin's lymphomas. Future Oncol. 2015;11(9):1327-1342.

Foster RH, Wiseman LR. Abciximab. An updated review of its use in ischaemic heart disease. Drugs. 1998;56(4):629-665.

Frenzel A, Schirrmann T, Hust M. Phage display-derived human antibodies in clinical development and therapy. MAbs. 2016;8(7):1177-1194. 
Fric J, Bertin-Maghit S, Wang CI, Nardin A, Warter L. Use of human monoclonal antibodies to treat Chikungunya virus infection. J Infect Dis. 2013;207(2):319-322.

Golay J, Da Roit F, Bologna L, Ferrara C, Leusen JH, Rambaldi A, et al. Glycoengineered CD20 antibody obinutuzumab activates neutrophils and mediates phagocytosis through $\mathrm{CD} 16 \mathrm{~B}$ more efficiently than rituximab. Blood. 2013;122(20):34823491.

Gorny MK. Human hybridoma technology. Antibody Technol J. 2012;2:1-5.

Goupille P. [Immunogenicity of biopharmaceuticals: Which consequences during the treatment of rheumatoid arthritis?]. Rev Med Interne. 2016;37(5):343-349.

Green LL. Transgenic mouse strains as platforms for the successful discovery and development of human therapeutic monoclonal antibodies. Curr Drug Discov Technol. 2014;11(1):74-84.

Hamze M, Meunier S, Karle A, Gdoura A, Goudet A, Szely $\mathrm{N}$, et al. Characterization of CD4 T cell epitopes of infliximab and rituximab identified from healthy donors. Front Immunol. 2017;8:500.

Hwang WY, Foote J. Immunogenicity of engineered antibodies. Methods. 2005;36(1):3-10.

Instituto Butantan. Butantan hyperimmune sera portfolio 2017 [cited 2017 December 1]. Available from: http://www.butantan. gov.br/producao/produtos/Paginas/default.aspx.

Jefferis R. Posttranslational modifications and the immunogenicity of biotherapeutics. J Immunol Res. 2016;2016:5358272.

Jones PT, Dear PH, Foote J, Neuberger MS, Winter G. Replacing the complementarity-determining regions in a human antibody with those from a mouse. Nature. 1986;321(6069):522-525.

Kaufmann SHE. Emil von Behring: translational medicine at the dawn of immunology. Nat Rev Immunol. 2017;17(6):341-343.

Kohler G, Milstein C. Continuous cultures of fused cells secreting antibody of predefined specificity. Nature. 1975;256(5517):495497.
Komarova TV, Sheshukova EV, Kosobokova EN, Serebryakova MV, Kosorukov VS, Tashlitsky VN, et al. Trastuzumab and pertuzumab plant biosimilars: modification of Asn297-linked glycan of the mabs produced in a plant with fucosyltransferase and xylosyltransferase gene knockouts. Biochemistry (Mosc). 2017;82(4):510-520.

Krause JC, Tsibane T, Tumpey TM, Huffman CJ, Basler CF, Crowe JE, Jr. A broadly neutralizing human monoclonal antibody that recognizes a conserved, novel epitope on the globular head of the influenza H1N1 virus hemagglutinin. J Virol. 2011;85(20):10905-10908.

Kymriah. FDA approval brings first gene therapy to the United States 2017 [cited 2017 December 1]. Available from: https:// www.fda.gov/NewsEvents/Newsroom/PressAnnouncements/ ucm574058.htm.

Lagasse HA, Alexaki A, Simhadri VL, Katagiri NH, Jankowski W, Sauna ZE, et al. Recent advances in (therapeutic protein) drug development. F1000Res. 2017;6:113.

Lamdan H, Gavilondo JV, Munoz Y, Pupo A, Huerta V, Musacchio A, et al. Affinity maturation and fine functional mapping of an antibody fragment against a novel neutralizing epitope on human vascular endothelial growth factor. Mol Biosyst. 2013;9(8):2097-2106.

Lawrence MS, Phillips KJ, Liu DR. Supercharging proteins can impart unusual resilience. J Am Chem Soc. 2007;129(33):1011010112.

Lee J, Boutz DR, Chromikova V, Joyce MG, Vollmers C, Leung $\mathrm{K}$, et al. Molecular-level analysis of the serum antibody repertoire in young adults before and after seasonal influenza vaccination. Nat Med. 2016;22(12):1456-1464.

Levine BL, Miskin J, Wonnacott K, Keir C. Global Manufacturing of CAR T Cell Therapy. Mol Ther Methods Clin Dev. 2017;4:92-101.

LifeSci. Human Antibody Discovery: Of Mice And Phage 2017 [cited 2017 December 6]. Available from: https://lifescivc. com/2017/05/human-antibody-discovery-mice-phage/.

Lippow SM, Wittrup KD, Tidor B. Computational design of antibody-affinity improvement beyond in vivo maturation. Nat Biotechnol. 2007;25(10):1171-1176. 
Lonberg N, Taylor LD, Harding FA, Trounstine M, Higgins KM, Schramm SR, et al. Antigen-specific human antibodies from mice comprising four distinct genetic modifications. Nature. 1994;368(6474):856-859.

Lopes dos Santos M, Yeda FP, Tsuruta LR, Horta BB, Pimenta AA, Jr., Degaki TL, et al. Rebmab200, a humanized monoclonal antibody targeting the sodium phosphate transporter $\mathrm{NaPi}$ b displays strong immune mediated cytotoxicity against cancer: a novel reagent for targeted antibody therapy of cancer. PLoS One. 2013;8(7):e70332.

Mendez MJ, Green LL, Corvalan JR, Jia XC, Maynard-Currie CE, Yang XD, et al. Functional transplant of megabase human immunoglobulin loci recapitulates human antibody response in mice. Nat Genet. 1997;15(2):146-156.

Miklos AE, Kluwe C, Der BS, Pai S, Sircar A, Hughes RA, et al. Structure-based design of supercharged, highly thermoresistant antibodies. Chem Biol. 2012;19(4):449-455.

Moody MA, Zhang R, Walter EB, Woods CW, Ginsburg GS, McClain MT, et al. H3N2 influenza infection elicits more cross-reactive and less clonally expanded antihemagglutinin antibodies than influenza vaccination. PLoS One. 2011;6(10):e25797.

Morrison SL, Johnson MJ, Herzenberg LA, Oi VT. Chimeric human antibody molecules: mouse antigen-binding domains with human constant region domains. Proc Natl Acad Sci U S A. 1984;81(21):6851-6855.

Murphy AJ, Macdonald LE, Stevens S, Karow M, Dore AT, Pobursky K, et al. Mice with megabase humanization of their immunoglobulin genes generate antibodies as efficiently as normal mice. Proc Natl Acad Sci U S A. 2014;111(14):51535158.

Muyldermans S, Smider VV. Distinct antibody species: structural differences creating therapeutic opportunities. Curr Opin Immunol. 2016;40:7-13.

Mvasi. FDA approves first biosimilar for the treatment of cancer 2017 [cited 2017 December 5]. Available from: https:// www.fda.gov/NewsEvents/Newsroom/PressAnnouncements/ ucm576112.htm.

Nelson AL. Antibody fragments: hope and hype. MAbs. 2010;2(1):77-83.
Norman DJ, Shield CF, 3rd, Barry J, Henell K, Funnell MB, Lemon J. A U.S. clinical study of Orthoclone OKT3 in renal transplantation. Transplant Proc. 1987;19(2 Suppl 1):21-27.

Ogivri. FDA approves first biosimilar for the treatment of certain breast and stomach cancers 2017 [cited 2017 December 5]. Available from: https:/www.fda.gov/NewsEvents/Newsroom/ PressAnnouncements/ucm587378.htm.

Osbourn J, Groves M, Vaughan T. From rodent reagents to human therapeutics using antibody guided selection. Methods. 2005;36(1):61-68.

Peters C, Brown S. Antibody-drug conjugates as novel anticancer chemotherapeutics. Biosci Rep. 2015;35(4).

Queen C, Schneider WP, Selick HE, Payne PW, Landolfi NF, Duncan JF, et al. A humanized antibody that binds to the interleukin 2 receptor. Proc Natl Acad Sci U S A. 1989;86(24):10029-10033.

Robbiani DF, Bozzacco L, Keeffe JR, Khouri R, Olsen PC, Gazumyan A, et al. Recurrent potent human neutralizing antibodies to Zika virus in Brazil and Mexico. Cell. 2017;169(4):597-609 e511.

Rother RP, Rollins SA, Mojcik CF, Brodsky RA, Bell L. Discovery and development of the complement inhibitor eculizumab for the treatment of paroxysmal nocturnal hemoglobinuria. Nat Biotechnol. 2007;25(11):1256-1264.

Rygiel K. Novel strategies for Alzheimer's disease treatment: An overview of anti-amyloid beta monoclonal antibodies. Indian $\mathrm{J}$ Pharmacol. 2016;48(6):629-636.

Saxena A, Wu D. Advances in therapeutic fc engineering modulation of igg-associated effector functions and serum half-life. Front Immunol. 2016;7:580.

Scheid JF, Mouquet H, Feldhahn N, Seaman MS, Velinzon $\mathrm{K}$, Pietzsch J, et al. Broad diversity of neutralizing antibodies isolated from memory B cells in HIV-infected individuals. Nature. 2009;458(7238):636-640.

Schmohl JU, Felices M, Oh F, Lenvik AJ, Lebeau AM, Panyam $\mathrm{J}$, et al. Engineering of Anti-CD133 trispecific molecule capable of inducing NK expansion and driving antibody-dependent cellmediated cytotoxicity. Cancer Res Treat. 2017;49(4):1140-1152. 
Smith GP. Filamentous fusion phage: novel expression vectors that display cloned antigens on the virion surface. Science. 1985;228(4705):1315-1317.

Smith SA, de Alwis AR, Kose N, Jadi RS, de Silva AM, Crowe JE, Jr. Isolation of dengue virus-specific memory B cells with live virus antigen from human subjects following natural infection reveals the presence of diverse novel functional groups of antibody clones. J Virol. 2014;88(21):12233-12241.

Smits NC, Sentman CL. Bispecific T-Cell engagers (BiTEs) as treatment of B-Cell lymphoma. J Clin Oncol. 2016;34(10):11311133.

Sondermann P, Szymkowski DE. Harnessing Fc receptor biology in the design of therapeutic antibodies. Curr Opin Immunol. 2016;40:78-87.

Stapleton NM, Andersen JT, Stemerding AM, Bjarnarson SP, Verheul RC, Gerritsen J, et al. Competition for FcRn-mediated transport gives rise to short half-life of human IgG3 and offers therapeutic potential. Nat Commun. 2011;2:599.

Stephenson KE, Barouch DH. Broadly Neutralizing Antibodies for HIV Eradication. Curr HIV/AIDS Rep. 2016;13(1):31-37.

Strohl WR. Current progress in innovative engineered antibodies. Protein Cell. 2018;9(1):86-120.

Tsurushita N, Hinton PR, Kumar S. Design of humanized antibodies: from anti-Tac to Zenapax. Methods. 2005;36(1):6983.

Tsuruta LR, Lopes Dos Santos M, Moro AM. Biosimilars advancements: Moving on to the future. Biotechnol Prog. 2015;31(5):1139-49.
Tsuruta LR, Lopes Dos Santos M, Yeda FP, Okamoto OK, Moro AM. Genetic analyses of Per.C6 cell clones producing a therapeutic monoclonal antibody regarding productivity and long-term stability. Appl Microbiol Biotechnol. 2016;100(23):10031-10041.

Wang X, Mathieu M, Brezski RJ. IgG Fc engineering to modulate antibody effector functions. Protein Cell. 2018;9(1):63-73.

Watier H, Reichert J. Evolution of antibody therapeutics. In: Vaughan T, Osbourn J, Jallal B, editors. Protein terapeutics: Wiley-VCH Verlag GmbH \& Co. KGaA; 2017. p. 25-49.

Weber CA, Mehta PJ, Ardito M, Moise L, Martin B, De Groot AS. T cell epitope: friend or foe? Immunogenicity of biologics in context. Adv Drug Deliv Rev. 2009;61(11):965-976.

Weiner GJ. Building better monoclonal antibody-based therapeutics. Nat Rev Cancer. 2015;15(6):361-370.

Wilson PC, Andrews SF. Tools to therapeutically harness the human antibody response. Nat Rev Immunol. 2012;12(10):709719.

Yescarta. FDA approves CAR-T cell therapy to treat adults with certain types of large B-cell lymphoma 2017 [cited 2017 December 1]. Available from: https://www.fda.gov/ NewsEvents/Newsroom/PressAnnouncements/ucm581216. htm.

Yu X, Tsibane T, McGraw PA, House FS, Keefer CJ, Hicar MD, et al. Neutralizing antibodies derived from the B cells of 1918 influenza pandemic survivors. Nature. 2008;455(7212):532-536. 